\title{
Ketoconazole modulates the infectivity of Ichthyophonus sp. (Mesomycetozoa) in vivo in experimentally injected European sea bass
}

\author{
Francisco Hontoria ${ }^{*}, \mathbf{M}^{\mathrm{a}}$ Angeles González, Ariadna Sitjà-Bobadilla, \\ Oswaldo Palenzuela, Pilar Alvarez-Pellitero
}

Instituto de Acuicultura Torre de la Sal (IATS-CSIC), 12595 Ribera de Cabanes, Castellón, Spain

\begin{abstract}
In vitro studies have confirmed the inhibitory effect of the azol-derivative ketoconazole (KZ) on the growth of Ichthyophonus, an important pathogen causing epizootics in wild and cultured fish. We evaluated the effect of KZ in vivo in European sea bass Dicentrarchus labrax experimentally infected with the same Ichthyophonus isolate. Liposomes were used to vehiculate different doses of KZ to increase the effect on Ichthyophonus and lower the toxicity of the drug, and $\mathrm{KZ}$ toxicity was assessed in cultured sea bass juveniles. We also studied the effect of liposomevehiculated KZ included in medicated food on ichthyophoniasis. KZ causes clear toxic effects in D. labrax juveniles at doses $>80 \mathrm{mg} \mathrm{kg}^{-1}$, apparent in the reduced survival of fish and histological alterations to livers, kidneys and spleens. Fish injected with Ichthyophonus and treated with KZ dosages of $\leq 80 \mathrm{mg} \mathrm{kg}^{-1} \mathrm{~d}^{-1}$ presented lower ichthyophoniasis prevalence, fewer organs infected per fish, and fewer spores in the affected organs than the untreated fish. KZ seems to delay the onset of infection, but cannot stop further progression once established. However, this behaviour is not clearly reflected in the biometric and haematological data collected from these fish. We hypothesise that KZ's delaying effect would increase, if lower infective doses (more similar to natural situations) were used. The drug administration vehicle (liposomes vs. emulsions) did not affect the results. Our data confirm the potential utility of KZ in treating ichthyophoniasis and reveal its low toxicity for sea bass. Nevertheless, the optimal dose and appropriate application protocol remain to be determined.
\end{abstract}

KEY WORDS: Ketoconazole $\cdot$ Ichthyophonus $\cdot$ Liposomes $\cdot$ Sea bass $\cdot$ Dicentrarchus labrax Resale or republication not permitted without written consent of the publisher

\section{INTRODUCTION}

Ichthyophonus is an obligate parasite with a wide host spectrum, including some freshwater or anadromous fish and numerous marine fish (McVicar 1998). The taxonomic position and identity of Ichthyophonus have been very controversial since its first description by Hofer (1893) from Salmo trutta. First considered a member of Protozoa (Caullery \& Mesnil 1905), the organism was ascribed to Fungi by Plehn \& Mulsow (1911), but this ascription was further questioned (reviewed in McVicar 1998). Molecular stud- ies have demonstrated that Ichthyophonus and other related microbes constitute a phylogenetic group at the boundaries of the animal-fungal divergence, which has been referred to as the 'DRIP' clade (Ragan et al. 1996, Spanggaard et al. 1996). Ichthyophonus was later ascribed to the class Mesomycetozoa (Mendoza et al. 2002); this class was included within the Opisthokonta but not within Fungi in the new classification of protists (Adl et al. 2005) based on recent molecular evidence.

Franco-Sierra et al. (1997) reported the discovery of an Ichthyophonus sp. in grey mullets and other 
marine fish from the Mediterranean area, and provided data on the infection in different mariculture systems. This isolate is genetically rather similar, but not identical, to other Ichthyophonus spp. isolates at the 18S rDNA locus (GenBank Accession Number FJ869836) (O. Palenzuela' unpubl. data). A detailed morphological study, including ultrastructural data, has also been published (Franco-Sierra \& AlvarezPellitero 1999).

Ichthyophonus is an important pathogen causing epizootics in wild and cultured fish (McVicar 1998). Presently, it is still considered a population-limiting factor affecting several commercially important fish species (Hershberger et al. 2010, Marty et al. 2010). No effective treatment of ichthyophoniasis is yet available: some treatments suggested for the first infection steps, such as fenoxetol and paraclorofenoxetol (Reichenbach-Klinke \& Elkan 1965) or antibiotics (Van Duijn 1956), proved to be ineffective, and prophylactic measures, such as the pasteurization of food (McVicar 1982) or disinfection (Herschberger et al. 2008), have also been suggested. In vitro studies have demonstrated the inhibitory effect of the antifungal agent ketoconazole (KZ) on Ichthyophonus growth (Chauvier \& Mortier-Gabet 1982, Hontoria et al. 2009). The preliminary in vitro and in vivo studies by Franco-Sierra (1994) also pointed to the promising effect of $\mathrm{KZ}$ on this parasite, especially when it was vehiculated in liposomes.

Azol-derivatives have been used as antifungal agents in human and veterinary medicine for decades. Among these agents, KZ has a broad spectrum of activity against both superficial and systemic mycosis. Its antifungal action is related to the inhibition of cytochrome P450-dependent demethylation of lanosterol in the biosynthetic pathway of ergosterol in fungi (Van den Bossche et al. 1988). However, it also inhibits a number of mammalian cytochromes, and thus it can cause liver damage through inhibition of NADH oxidase and therefore can affect mitochondrial activity (Rodríguez \& Acosta 1996). Besides its antifungal properties, KZ has also been proposed for application in cancer chemotherapy (Wang et al. 2002) and to potentiate the effect of treatments against resistant helminths (Bartley et al. 2012, Devine et al. 2012).

Liposomes are spherical soft-matter particles consisting of 1 or more bilayer membranes, and are most commonly composed of phospholipids encapsulating a volume of aqueous medium. Liposomes are readily prepared in the laboratory (Jesorka \& Orwar 2008). The aqueous medium is typically the same as that in which the liposomes are suspended. Therefore, it can be manipulated to contain the desired substances isolated from the surroundings.

Liposomes were first proposed and tested as a drug delivery system $>30 \mathrm{yr}$ ago. Since then, the design of constructs for use in the treatment and prevention of disease has substantially improved (Gregoriadis 1995, Torchilin 2005), and a reduction in the toxicity of several drugs when encapsulated in liposomes has been reported (Mehta 1996). Consequently, the use of liposomes as a delivering agent for KZ may provide different advantages related to the protection against drug toxicity and the improvement of treatments, since liposomes may more efficiently reach the tissues and internal locations in which the endoparasites dwell.

Recent in vitro studies (Hontoria et al. 2009) confirmed the above-mentioned inhibitory effect of KZ on Ichthyophonus growth and endorsed its potential use in the treatment of ichthyophoniasis. These previously available data related to in vitro studies prompted us to conduct in vivo studies on the effect of $\mathrm{KZ}$ on ichhyophoniasis, using European sea bass Dicentrarchus labrax L. as a fish model. The drug was delivered in liposomes or lipid emulsions. After testing and discarding the possible toxic effect of the drug being intracoelomically (i.c.) injected into fish, the effect of orally administered KZ was evaluated in fish experimentally infected with Ichthyophonus sp.

\section{MATERIALS AND METHODS}

A preliminary dose-response toxicity test to assess the noxious effect of antifungal KZ on European sea bass Dicentrarchus labrax was performed prior to the treatment test in which the drug was delivered with the food to treat experimentally Ichthyophonusinfected fish. The first test served also to calibrate the dosage to be employed in the second test. Both experiments were conducted in the facilities of the Instituto de Acuicultura Torre de la Sal (IATS).

\section{Preliminary dose-response toxicity test}

\section{Experimental design}

To evaluate the toxicity of KZ to sea bass, 4 doses of KZ $\left(20,40,80\right.$ and $160 \mathrm{mg} \mathrm{kg}^{-1}$ fish) were tested. European sea bass weighing approximately $30 \mathrm{~g}$ (20 fish group $^{-1}$ ) were allocated to 2501 fibreglass tanks and injected i.c. with $100 \mu \mathrm{l}$ of each assayed formulation on Days 0, 2, 4, 6, 8 and 10. KZ was deliv- 
ered encapsulated in liposomes. Controls consisted of fish not injected but handled in the same way as the treated animals (C) and fish injected with an equivalent amount of liposomes used at the highest dose (KZ-160L) but without KZ (CL). Ten fish per group were sampled on Day 15 after the first injection (p.i.). Details of the experimental protocol and sampling can be found in Table 1.

Preparation of liposomes and KZ formulations

Liposomes were prepared with phosphatidylcholine extracted from egg yolk (EPC; Avanti Polar Lipids). Palmitic (16:0, $34 \%$ [w/w] of total fatty acids) and oleic $(18: 1,31 \%$ [w/w]) acids are the main fatty acids in EPC. EPC also contains 18\% (w/w) linoleic acid (18:2). Cholesterol (CHO; Sigma-Aldrich Química) was always included as a membrane stabilizer, and stearylamine (ST), a polar derivative of stearic acid (Sigma-Aldrich Química), was incorporated in the liposomes used in the toxicity tests as charged lipid to prevent aggregation. In the case of the treatment formulations, $20 \%$ (w/w) KZ (Acofarma) was incorporated into the liposome composition. The liposomes in the form of multilamellar vesicles were prepared according to the method proposed by Bangham et al. (1965), but using Eagle's minimum essential medium (MEM-10; see 'Ichthyophonus source and culture media' for composition) as the aqueous phase. Briefly, the lipid mixture dissolved in chloroform was dried under nitrogen flux in a thin layer on the bottom of a flask and rehydrated with the corresponding aqueous phase for $1 \mathrm{~h}$ by vortexing frequently until an homogenous suspension of liposomes was achieved. The composition of the lipid mixture for stock preparation used in the treatment liposomes for the toxicity test was EPC:KZ:CHO:ST (56:20:19:5 w/w) and EPC:CHO:ST (76:19:5 w/w) in

Table 1. Dicentrarchus labrax. Experimental groups of European sea bass to test the toxicity of injected ketoconazole (KZ). Twenty fish were set initially in each group. Ten fish per group were sampled on Day 15 after the first injection

\begin{tabular}{|lcc|}
\hline Group & \multicolumn{1}{c}{ Treatment } & $\begin{array}{c}\text { No. of fish } \\
\text { sampled }\end{array}$ \\
\hline $\mathrm{C}$ & Control non-injected & 10 \\
$\mathrm{CL}$ & Control liposomes & 10 \\
$\mathrm{KZ}-20 \mathrm{~L}$ & $20 \mathrm{mg} \mathrm{KZ} \mathrm{kg}^{-1}$ in liposomes & 10 \\
$\mathrm{KZ}-40 \mathrm{~L}$ & $40 \mathrm{mg} \mathrm{KZ} \mathrm{kg}^{-1}$ in liposomes & 10 \\
KZ-80L & $80 \mathrm{mg} \mathrm{KZ} \mathrm{kg}^{-1}$ in liposomes & 10 \\
KZ-160L & $160 \mathrm{mg} \mathrm{KZ} \mathrm{kg}^{-1}$ in liposomes & 10 \\
\hline
\end{tabular}

the control liposomes without KZ. These mixtures were rehydrated with MEM-10 to achieve a concentration of $240 \mathrm{mg}$ lipid $\mathrm{ml}^{-1}$. This was the concentration utilised for the control liposome injections without $\mathrm{KZ}$ and for the highest dose employed to reach $160 \mathrm{mg} \mathrm{KZ} \mathrm{kg}{ }^{-1}$ live fish biomass by injecting $100 \mu \mathrm{l}$ to fish of $30 \mathrm{~g}$ mean wet weight. In the rest of the injection treatments, the liposome suspension was diluted as necessary $(1 / 2,1 / 4$, or $1 / 8)$ to reach the experimental doses for each fish.

Sampling and histological procedures

Fish were overdosed with the anaesthetic MS-222 (Sigma), weighed, measured and necropsied. The condition factor $(\mathrm{CF})$ was calculated as $\mathrm{CF}=\left(W / L^{3}\right) \times$ $100 \%$, where $W=$ weight $(g)$ and $L=$ [total] length $(\mathrm{cm})^{\prime}$. Survival was calculated as the percentage of animals alive at the end of the experiment from the 20 fish group $^{-1}$ initially set.

Fish were bled from the caudal vein, and 1 blood aliquot was immediately used to count the number of red blood cells (RBC, number of red blood cells per cubic millimetre) using an haemocytometer; another aliquot was drawn into heparinised capillary tubes and centrifuged at $1500 \times g$ for $30 \mathrm{~min}$. The haematocrit $(\mathrm{Hc})$ was determined as the percentage of whole blood volume that consisted of RBCs, and another aliquot was used to measure the haemoglobin concentration $\left(\mathrm{Hb}, \mathrm{g} \mathrm{l}^{-1}\right)$ with a HemoCue B-Haemoglobin Analyser ${ }^{\circledR}$ (AB, Leo Diagnostic), which uses a modified azide methaemoglobin reaction for haemoglobin quantification. Mean corpuscular haemoglobin content $(\mathrm{MCH})$ in picograms per cell, mean corpuscular haemoglobin concentration (MCHC) in picograms per 100 cubic microns and mean corpuscular volume (MCV) in cubic microns were calculated.

Tissue portions of anterior and posterior kidney, spleen and liver from 5 treated and 5 control fish were fixed in $10 \%$ buffered formalin and embedded in Paraplast ${ }^{\circledR}$. Sections (5 to $7 \mathrm{~mm}$ ) were stained with haematoxylin and eosin, periodic acid Schiff, or Grocott stainings. Very thin sections ( 1 to $3 \mu \mathrm{m}$ ) were obtained from material fixed with $2.5 \%$ glutaraldehyde, embedded in Historesin (Leica) and stained with toluidine blue.

The haematopoietic activity was evaluated semiquantitatively by the abundance of young blood cells (according to their staining characteristics) in the corresponding organ. 


\section{Experimental treatments}

\section{Ichthyophonus source and culture media}

The Ichthyophonus used in this study was obtained from wild grey mullets (Mugil capito and Liza saliens) captured in the River Ebro Delta (NE Spain) during an epizootic event (Franco-Sierra et al. 1997). Pieces of liver and trunk kidney were aseptically excised and seeded in MEM-10. After germination and growth of Ichthyophonus hyphae, organs were removed and cultures were axenised through serial passages in the same medium. Since its original isolation, Ichthyophonus culture has been maintained through serial passages in $100 \mathrm{ml}$ bottles containing MEM-10 and under the conditions described in previous studies (Franco-Sierra 1994, Franco-Sierra \& Alvarez-Pellitero 1999) ( $\mathrm{pH} 7.2$ and $14^{\circ} \mathrm{C}$ ). Ichthyophonus from routine cultures was replicated in the same medium and conditions in T-25 flasks, to obtain the amount necessary for the tests.

Ichthyophonus was cultured in Eagle's minimum essential medium (Sigma M5775) (MEM) at pH 7.2, supplemented with $20 \mathrm{mM}$ HEPES (Gibco), 10\% (w/v) foetal bovine serum (FBS) (Sigma F4010) (MEM-10) and $50 \mu \mathrm{g} \mathrm{ml}^{-1}$ gentamycin.

\section{Preparation of liposomes, lipid emulsions and $\mathrm{KZ}$ formulations}

Liposomes included in the medicated food utilised in the experimental treatment were also made of phosphatidylcholine extracted from EPC and $\mathrm{CHO}$ as a membrane stabilizer. The addition of ST was not considered necessary in the formulations used to treat the food pellets, since they were dried before use. Instead, $200 \mathrm{mg} \mathrm{ml}^{-1}$ sucrose was dissolved in the aqueous phase to prevent damage in the bilayer membrane during rehydration (Hontoria et al. 1994). As in the toxicity experiments, the treatment formulations were supplied with $20 \%$ (w/w) KZ. Multilamellar liposomes were prepared as in the injected formulations in the toxicity tests, but using seawater with sucrose instead of MEM as the aqueous phase, as explained above. The composition of the liposomes utilised to medicate the food pellets was EPC:KZ:CHO (60:20:20 w/w). In this case the lipid concentration used was $20 \mathrm{mg} \mathrm{ml}^{-1}$. The lipid emulsions were prepared by emulsifying triacylglyceride triolein (TON) with Tween 80 (polysorbate 80; Sigma-Aldrich Química) in seawater, using an IKA Ultra-Turrax tissue disruptor (IKA
Labortechnik) at high lipid concentration (625 mg $\mathrm{ml}^{-1}$ ) in order to improve the stability. The composition of this stock emulsion was seawater:TON: Tween80 (46.5:37.9: 15.6 v/v). KZ was added to the emulsified mixture, for a final concentration of $4 \mathrm{mg}$ $\mathrm{ml}^{-1}$ after dilution, and mixed carefully. The emulsion with $\mathrm{KZ}$ was then diluted to a final lipid concentration of $20 \mathrm{mg} \mathrm{ml}^{-1}$.

\section{Preparation of medicated food}

KZ was prepared with liposomes or emulsions as explained above. The corresponding preparations were incorporated into commercial sea bass food pellets (ProAqua Nutrición, Dueñas, Spain) in the amount necessary to obtain doses of 40 and $80 \mathrm{mg}$ $\mathrm{kg}^{-1}$ fish $\mathrm{d}^{-1}$, considering a food intake of $2.5 \%$ of body weight (1.6 and $3.2 \mathrm{mg} \mathrm{KZ} \mathrm{g}^{-1}$ pellets, respectively). Then, the pellets were dried at room temperature prior to use. Care was taken to employ fresh liposomes, emulsions and medicated pellets, i.e. prepared $<3 \mathrm{~d}$ before use.

\section{Experimental design}

European sea bass (mean weight $=45 \mathrm{~g}$ ) were allocated to 2501 experimental tanks (30 fish per experimental diet separated into 2 replicate tanks of 15 fish each for each experimental group) and fed the experimental diets starting on Day 0. Medicated food was administered daily at an amount of $2.5 \%$ of fish weight starting on Day 0 and continuing over $35 \mathrm{~d}$. According to the results of toxicity experiments, the doses corresponding to 40 and $80 \mathrm{mg} \mathrm{kg}^{-1} \mathrm{fish} \mathrm{d}^{-1}$ were chosen.

Ichthyophonus exposure was performed on Day 7. Ichthyophonus inoculum was collected from in vitro culture in MEM, washed with PBS and concentrated

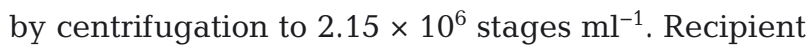
fish were inoculated i.c. with $0.05 \mathrm{ml}$ of inoculum

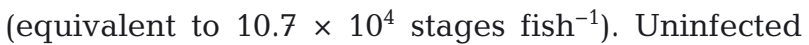
control fish received an equal amount of PBS without inoculum.

Experimental groups included uninfected controls receiving untreated food (C), Ichthyophonusinfected and untreated fish (C-Ich), Ichthyophonusinfected and treated fish (KZ-Ich-40L and KZ-Ich80L; KZ-Ich-40E and KZ-Ich-80E), and uninfected and treated fish (KZ-80L and KZ-80E). Fish (10 fish group $^{-1}, 5$ from each replicate tank) were sampled on Days 21 and 35 after the initiation of treatment 
(Days 14 and 28 p.i.). Details on the experimental protocol and samplings can be found in Table 2 .

Sampling, histological procedures and evaluation of intensity

The fish sampling and histological processing were performed as described for the toxicity test. Ichthyophonus intensity was evaluated in histological sections of anterior and posterior kidney, spleen, heart and liver, which are considered the target organs according to previous data (Franco-Sierra 1994). The number of infected organs in each fish was registered, and the spores per microscope field at $120 \times$ were counted (3 fields for kidney and spleen; 5 fields for liver). Parasite stages were differentiated as viable and necrotic, the latter usually being degenerated inside granulomata. For prevalence calculations, fish were considered histology-positive when parasite stages were found in at least one of the examined organs.

\section{Statistical analyses}

Biometric and haematological final data from both the preliminary toxicity test and the experimental treatments were compared using different 1-way ANOVA tests, with the Brown-Forsythe transformation in search of differences among treatments, followed by Games-Howell's test for multiple mean comparisons when appropriate. Both tests are robust in cases of variance heteroscedasticity (Brown \& Forsythe 1974, Games \& Howell 1976); heteroscedasticity occurs in this study because of the high dispersion of the final data. The same statistical treatment was applied to the data on the number of organs with parasites per fish and on the number of spores per microscope field counted in each treatment after 21 and 35 (final) d of medicated feeding.

\section{RESULTS}

\section{Toxicity test}

Survival and haematological data are presented in Table 3. Only the KZ-160L treatment clearly affected fish survival, as only 1 fish (5\%) was alive at the end of the experiment. No appreciable differences in fish weight, length, or CF were observed in any experimental group with respect to the controls (data not shown).

Some haematological values changed with treatments. Hb was significantly higher in 3 out of 5 treated groups (except KZ-40L and KZ-160L) than in the $\mathrm{C}$ group. No significant differences were observed in $\mathrm{Hc}$ or RBC between groups. In contrast, the only surviving fish from the KZ-160L group had markedly lower $\mathrm{Hc}$ and the highest RBC value. Accordingly, MCV was very low in KZ-160L fish, but no differences were detected among the other groups. Compared to the $\mathrm{C}$ group, MCHC was significantly higher in the KZ-20L and CL groups and $\mathrm{MCH}$ was significantly higher in the KZ-20L group. The lowest value of $\mathrm{MCH}$ was again registered in the KZ-160L fish, while the MCHC was remarkably high.

Histological observations of the studied organs are detailed in Table 4 and Figs. 1 to 10. Some changes were detected in the studied organs of KZ-treated fish. The percentage of fish with increased haematopoietic activity in the spleen was higher in the KZ20L, KZ-40L and KZ-80L groups than in controls,

Table 2. Dicentrarchus labrax. Experimental groups of European sea bass treated with ketoconazole (KZ) after their injection with Ichthyophonus sp. (Ich) on Day 7 after the start of the treatment. Thirty fish were set initially for each group separated into 2 replicates of 15 fish. Ten fish were sampled twice in each group (each time 5 from each replicate)

\begin{tabular}{|llcc|}
\hline Group & \multicolumn{1}{c|}{ Treatment } & $\begin{array}{c}\text { Ichthyophonus } \\
\text { injection }\end{array}$ & $\begin{array}{c}\text { Medicated food } \\
(0-35 \mathrm{~d})\end{array}$ \\
\hline $\mathrm{C}$ & Control untreated and non-infected & No & No \\
C-Ich & Control untreated and infected & Yes & No \\
KZ-80L & Control $80 \mathrm{mg} \mathrm{KZ} \mathrm{kg}^{-1} \mathrm{~d}^{-1}$ in liposomes and non-infected & No & Yes \\
KZ-80E & Control $80 \mathrm{mg} \mathrm{KZ} \mathrm{kg}^{-1} \mathrm{~d}^{-1}$ in emulsion and non-infected & No & Yes \\
KZ-Ich-40L & $40 \mathrm{mg} \mathrm{KZ} \mathrm{kg}^{-1} \mathrm{~d}^{-1}$ in liposomes and infected & Yes & Yes \\
KZ-Ich-80L & $80 \mathrm{mg} \mathrm{KZ} \mathrm{kg}^{-1} \mathrm{~d}^{-1}$ in liposomes and infected & Yes & Yes \\
KZ-Ich-40E & $40 \mathrm{mg} \mathrm{KZ} \mathrm{kg}^{-1} \mathrm{~d}^{-1}$ in emulsion and infected & Yes & Yes \\
KZ-Ich-80E & $80 \mathrm{mg} \mathrm{KZ} \mathrm{kg}^{-1} \mathrm{~d}^{-1}$ in emulsion and infected & Yes & Yes \\
\hline
\end{tabular}


Table 3. Dicentrarchus labrax. Toxicity test. Mean (SD) survival and haemotological values at the final sampling (Day 15 after the first injection). Hb: haemoglobin concentration; Hc: haematocrit level; RBC: red blood cells; MCH: mean corpuscular haemoglobin content; MCHC: mean corpuscular haemoglobin concentration; MCV: mean cellular volume. Different superscripts within a column indicate significant differences between groups (ANOVA and Games-Howell tests; $\mathrm{p} \leq 0.05$ ). Group abbreviations as in Table 1

\begin{tabular}{|c|c|c|c|c|c|c|c|}
\hline Group & $\begin{array}{c}\text { Survival } \\
(\%)^{1}\end{array}$ & $\begin{array}{l}\mathrm{Hb} \\
\left(\mathrm{g} \mathrm{l}^{-1}\right)\end{array}$ & $\begin{array}{l}\mathrm{Hc} \\
(\%)\end{array}$ & $\begin{array}{c}\mathrm{RBC} \\
\left(10^{6} \mathrm{~mm}^{-3}\right)\end{array}$ & $\begin{array}{c}\mathrm{MCH} \\
\left(\text { pg cell }^{-1}\right)\end{array}$ & $\begin{array}{c}\text { MCHC } \\
\left(\operatorname{pg} 10^{-2} \mu \mathrm{m}^{-3}\right)\end{array}$ & $\begin{array}{l}\mathrm{MCV} \\
\left(\mu \mathrm{m}^{3}\right)\end{array}$ \\
\hline $\mathrm{C}$ & 100 & $76.80(11.20)^{\mathrm{a}}$ & $35.40(3.80)^{\mathrm{a}}$ & $2.78(0.55)^{\mathrm{a}}$ & $27.90(5.50)^{\mathrm{a}}$ & $21.90(3.70)^{\mathrm{a}}$ & $130.80(32.40)^{\mathrm{a}}$ \\
\hline $\mathrm{CL}$ & 95 & $98.90(13.70)^{\mathrm{bc}}$ & $36.00(5.10)^{\mathrm{a}}$ & $3.04(0.44)^{\mathrm{a}}$ & $33.00(5.80)^{\mathrm{ab}}$ & $27.70(3.60)^{\mathrm{bc}}$ & $119.80(18.60)^{\mathrm{a}}$ \\
\hline KZ-20L & 100 & $105.00(14.40)^{\mathrm{C}}$ & $35.30(6.30)^{\mathrm{a}}$ & $2.87(0.34)^{\mathrm{a}}$ & $36.70(4.30)^{\mathrm{b}}$ & $30.20(4.40)^{\mathrm{C}}$ & $123.10(18.40)^{\mathrm{a}}$ \\
\hline $\mathrm{KZ}-40 \mathrm{~L}$ & 100 & $86.30(16.30)^{\mathrm{ab}}$ & $38.90(9.50)^{\mathrm{a}}$ & $3.18(0.28)^{\mathrm{a}}$ & $27.30(5.40)^{\mathrm{a}}$ & $22.80(5.10)^{\mathrm{ab}}$ & $123.10(33.80)^{\mathrm{a}}$ \\
\hline KZ-80L & 90 & $101.60(12.10)^{\mathrm{bc}}$ & $43.60(6.80)^{\mathrm{a}}$ & $3.20(0.38)^{\mathrm{a}}$ & $32.20(5.50)^{\mathrm{ab}}$ & $23.40(4.10)^{\mathrm{ab}}$ & $139.50(27.10)^{\mathrm{a}}$ \\
\hline KZ-160L & 5 & $78.00^{1}$ & $26.00^{1}$ & $5.610^{1}$ & $13.90^{1}$ & $30.00^{1}$ & $46.30^{1}$ \\
\hline
\end{tabular}

Table 4. Dicentrarchus labrax. Toxicity test. Histological observations (\% of observations) of different European sea bass tissues collected at the final sampling (Day 15 after the first injection). MMC: melanomacrophagic centres. Group abbreviations as in Table 1

\begin{tabular}{|c|c|c|c|c|c|c|c|c|c|c|c|c|c|}
\hline \multirow[t]{2}{*}{ Group } & \multicolumn{6}{|c|}{$\begin{array}{c}\text { Haemopoietic activity } \\
\text { Kidney } \quad \text { Spleen } \_ \text {_ }\end{array}$} & \multicolumn{4}{|c|}{$\longrightarrow$ Kidney $\quad$ MMC - Spleen } & \multicolumn{3}{|c|}{ — Alterations/necrosis - } \\
\hline & & $\begin{array}{l}\text { Kidney } \\
\text { Medium }\end{array}$ & $\overline{\text { High }}$ & Slight & $\begin{array}{l}\text { - Spleen - } \\
\text { Medium }\end{array}$ & $\overline{\text { High }}$ & $\begin{array}{l}\text { K } \\
\text { Scarce }\end{array}$ & Kidney & $\begin{array}{r}\mathrm{S} \\
\text { Scarce }\end{array}$ & $\begin{array}{l}\text { pleen } \\
\text { Abundant }\end{array}$ & Absent & $\begin{array}{l}\text { Liver } \\
\text { Moderate }\end{array}$ & $\overline{\text { High }}$ \\
\hline C & 0 & 20 & 80 & 100 & 0 & 0 & 100 & 0 & 100 & 0 & 80 & 20 & 0 \\
\hline CL & 0 & 40 & 60 & 25 & 75 & 0 & 100 & 0 & 75 & 25 & 100 & 0 & 0 \\
\hline KZ-20L & 0 & 100 & 0 & 0 & 60 & 40 & 100 & 0 & 40 & 60 & 80 & 20 & 0 \\
\hline KZ-40L & 0 & 40 & 60 & 0 & 100 & 0 & 50 & 50 & 0 & 100 & 0 & 50 & 50 \\
\hline KZ-80L & 0 & 40 & 60 & 20 & 60 & 20 & 0 & 100 & 0 & 100 & 60 & 40 & 0 \\
\hline KZ-160L & 0 & 100 & 0 & 100 & 0 & 0 & 0 & 0 & 50 & 50 & 0 & 0 & 100 \\
\hline
\end{tabular}
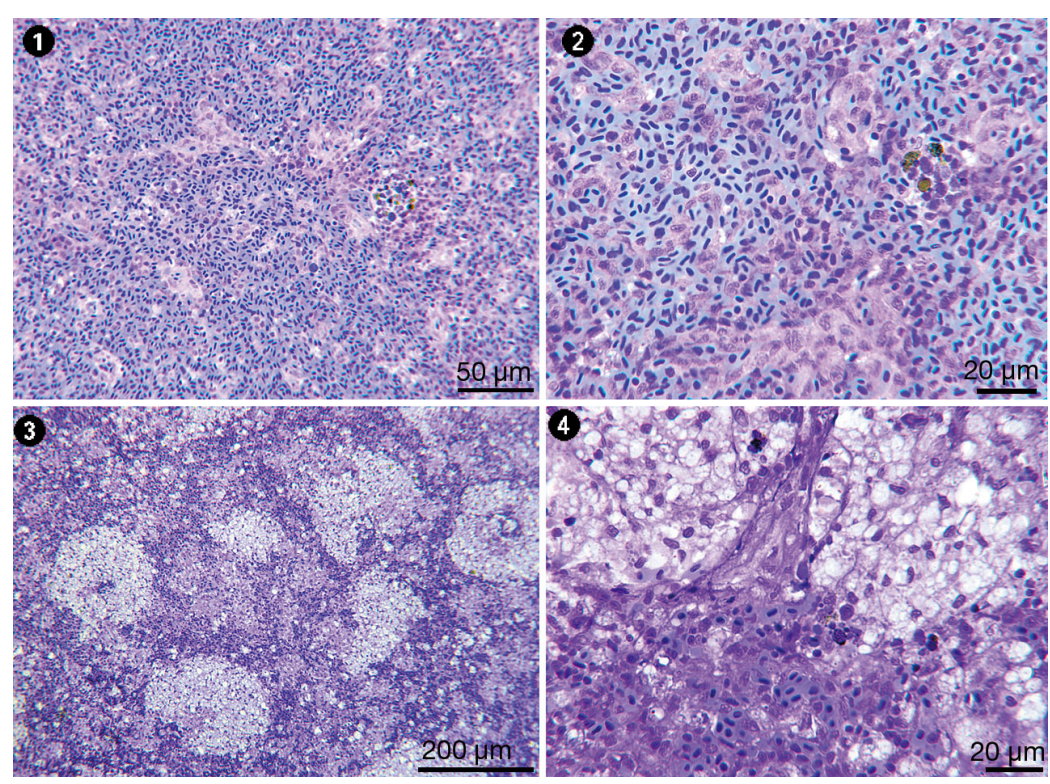

Figs. 1 to 4. Dicentrarchus labrax. Histological sections of spleen of European sea bass non-injected (control, C) or injected with ketoconazole in liposomes (80 or $160 \mathrm{mg} \mathrm{kg}^{-1}$ of fish; KZ-80L, KZ-160L). Figs. 1 \& 2. Spleen of C fish. Fig. 3. Spleen of KZ-160L fish. Fig. 4. Spleen of KZ-80L fish. Note the lipid accumulations (white spots), especially in KZ-160L fish. Staining: Toluidine blue whereas KZ-160L fish showed lower haematopoietic activity. However, the spleenic tissue architecture was altered in treated fish with respect to C fish (Figs. 1 to 4 ), with some lipid accumulations much more evident in KZ-160L fish (Fig. 3). No important changes were detected in the anterior kidney haematopoietic activity in treated groups with respect to controls, though some lipid accumulations were also present in treated fish (Figs. 5 to 8). The percentage of fish with abundant melanomacrophagic centres (MMC) was generally higher in the treated fish, especially in the spleen, with the exception of the KZ160L group in which no MMCs were seen in the kidney (Fig. 7). Hepatic alterations were absent or slight in most controls and KZ-20L fish, whereas more KZ-40L and KZ-80L fish had slight or moderate lesions, 
and all the KZ-160L surviving fish presented high alterations. The surviving KZ-160 fish presented marked steatosis (Fig. 9), in contrast with the moderate alterations with certain lipid accumulation in some KZ-80L fish (Fig. 10).
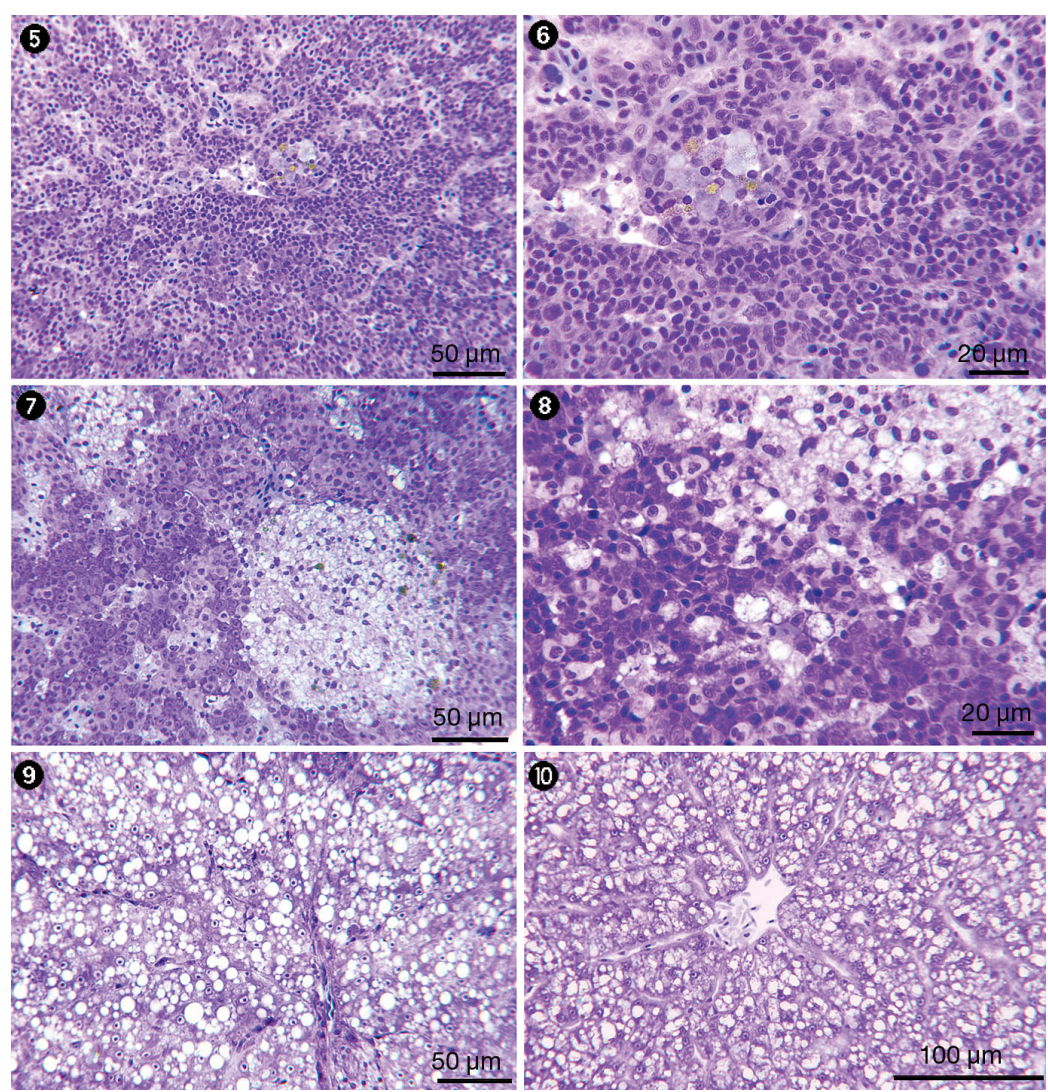

Figs. 5 to 10. Dicentrarchus labrax. Histological sections of (Figs. 5 to 8) head kidney and (Figs. 9 \& 10) liver of European sea bass non-injected (control, C) or injected with ketoconazole in liposomes (80 or $160 \mathrm{mg} \mathrm{kg}^{-1}$ of fish; KZ-80L, KZ-160L). Figs. 5 \& 6. Head kidney of C fish. Fig. 7. Head kidney of KZ-160L fish. Fig. 8. Head kidney of KZ-80L fish. Certain accumulation of lipids can be seen. Fig. 9. Liver steatosis is evident in KZ-160L fish. Fig. 10. Tissue architecture is unaffected in KZ-80L fish. Staining: Toluidine blue

\section{Experimental treatments}

No differences between groups were found regarding length, weight or $\mathrm{CF}$ at either 21 or $35 \mathrm{~d}$ after the start of the treatment (data not shown). The infection did not clearly affect measured haematological parameters (Table 5). However, some differences were detected between treated and nontreated fish. On Day 21 p.t., only Hc was significantly higher in KZ-Ich-40E (34.8 \pm 7.9) fish than in C-Ich fish (24.4 \pm 5.6). Hb, MCH, MCHC and $\mathrm{MCV}$ presented no differences between KZ-treated and KZ-untreated fish irrespective of their status of infection (data not shown). However, on Day 35 p.t. more significant differences were observed, though only between some liposome and emulsion treatments. Thus, Hc was significantly higher and $\mathrm{MCHC}$ lower in KZ-Ich80L than in KZ-Ich-80E fish; and $\mathrm{MCH}$ was significantly higher in KZ-Ich-40L than in KZ-Ich-40E fish. Other observed differences for other haematological parameters were not statistically significant in the ANOVA test due to high individual variability. The case of the particularly high MCV value in KZ-Ich-80L fish illustrates this circumstance. For the sake of clarity, the data for the non-infected (C) and medicated (KZ-80L/-E) groups have been omitted from Table 5, since no differences between the 2 groups were detected.

Prevalence of infection of Ichthyophonus was higher in C-Ich than in

Table 5. Dicentrarchus labrax. Mean (SD) haematological values at the last sampling (Day 35 post-treatment) of control (C) and ketoconazole (KZ) orally treated European sea bass after experimental injection with Ichthyophonus sp. Group abbreviations as in Table 2. Parameter abbreviations and statistical tests as in Table 3

\begin{tabular}{|lcccccc|}
\hline Group & $\begin{array}{c}\mathrm{Hb} \\
\left(\mathrm{g} \mathrm{l}^{-1}\right)\end{array}$ & $\begin{array}{c}\mathrm{HC} \\
(\%)\end{array}$ & $\begin{array}{c}\mathrm{RBC} \\
\left(10^{6} \mathrm{~mm}^{-3}\right)\end{array}$ & $\begin{array}{c}\mathrm{MCH} \\
\left(\mathrm{pg} \mathrm{cell}^{-1}\right)\end{array}$ & $\begin{array}{c}\mathrm{MCHC} \\
\left(\mathrm{pg} \mathrm{10}^{-2} \mu \mathrm{m}^{-3}\right)\end{array}$ & $\begin{array}{c}\mathrm{MCV} \\
\left(\mu \mathrm{m}^{3}\right)\end{array}$ \\
\hline C & $78.00(7.90)^{\mathrm{a}}$ & $41.80(7.80)^{\mathrm{ab}}$ & $3.12(0.60)^{\mathrm{a}}$ & $25.40(3.00)^{\mathrm{ab}}$ & $19.00(3.40)^{\mathrm{ab}}$ & $140.70(28.80)^{\mathrm{a}}$ \\
C-Ich & $71.90(8.90)^{\mathrm{a}}$ & $38.10(11.40)^{\mathrm{ab}}$ & $3.17(1.02)^{\mathrm{a}}$ & $24.30(5.80)^{\mathrm{ab}}$ & $20.00(4.20)^{\mathrm{ab}}$ & $128.30(44.60)^{\mathrm{a}}$ \\
KZ-ICh-40L & $71.80(8.30)^{\mathrm{a}}$ & $35.30(8.50)^{\mathrm{ab}}$ & $2.57(0.39)^{\mathrm{a}}$ & $28.30(3.30)^{\mathrm{b}}$ & $21.20(3.50)^{\mathrm{ab}}$ & $138.50(26.70)^{\mathrm{a}}$ \\
KZ-Ich-80L & $75.50(8.40)^{\mathrm{a}}$ & $45.20(11.60)^{\mathrm{b}}$ & $2.83(0.41)^{\mathrm{a}}$ & $27.00(3.80)^{\mathrm{ab}}$ & $17.60(4.00)^{\mathrm{a}}$ & $160.30(37.20)^{\mathrm{a}}$ \\
KZ-Ich-40E & $71.40(6.90)^{\mathrm{a}}$ & $37.90(8.20)^{\mathrm{ab}}$ & $3.43(1.08)^{\mathrm{a}}$ & $22.60(6.00)^{\mathrm{a}}$ & $19.60(4.40)^{\mathrm{ab}}$ & $122.90(44.00)^{\mathrm{a}}$ \\
KZ-Ich-80E & $74.40(8.90)^{\mathrm{a}}$ & $34.60(9.20)^{\mathrm{a}}$ & $2.74(0.62)^{\mathrm{a}}$ & $27.90(4.50)^{\mathrm{b}}$ & $22.10(4.10)^{\mathrm{b}}$ & $134.00(38.80)^{\mathrm{a}}$ \\
\hline
\end{tabular}


KZ-Ich fish, particularly on Day 21 p.t., though differences were reduced at the final sampling (Day 35 p.t.), when the lowest value was registered for KZIch-80E fish (Fig. 11, Table 6).

In addition, most differences between $\mathrm{C}$-Ich- and KZ-Ich-infected fish regarding the number of spores per field and per fish were not statistically significant, due to high individual variability. However, both the mean number of organs with parasites and the mean number of spores per field and per fish showed a clear trend to higher values in C-Ich fish compared to those of treated fish at both sampling times (Figs. 12 \& 13).

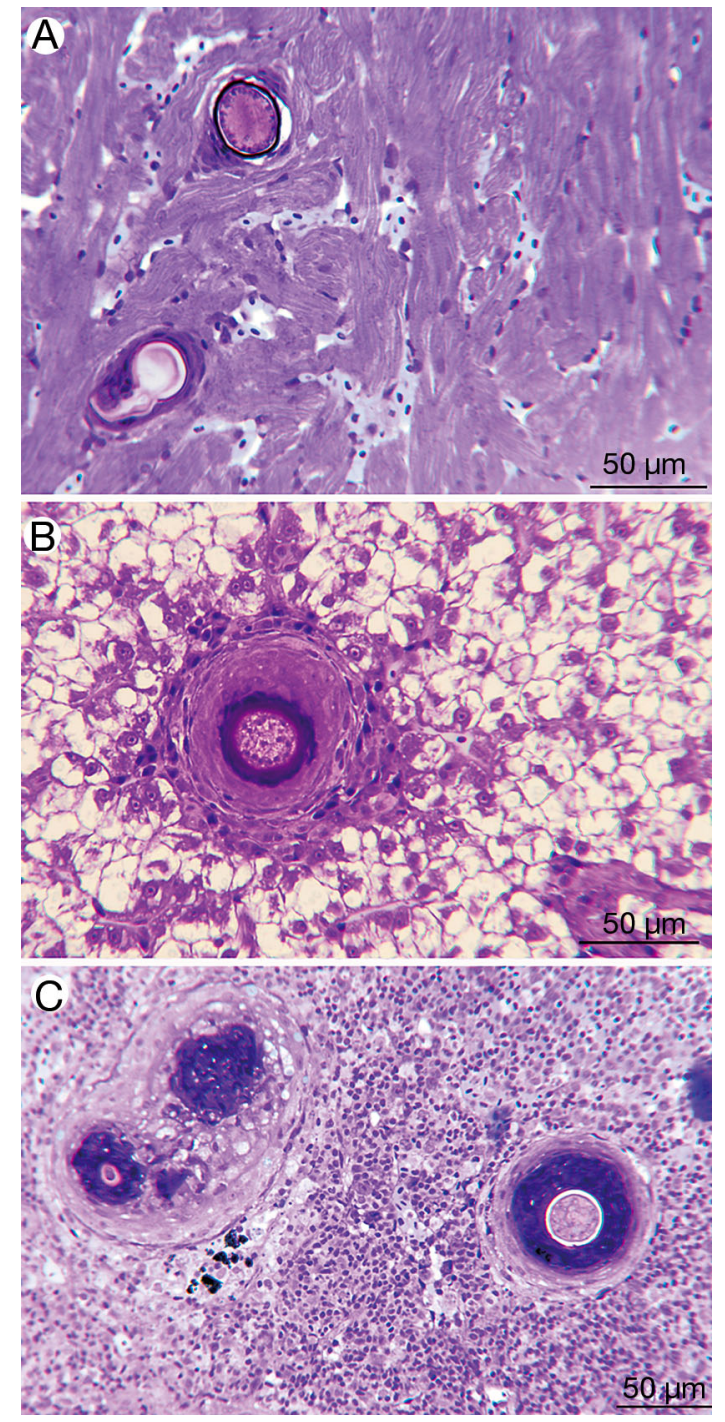

Fig. 11. Dicentrarchus labrax. European seabass injected with Ichthyophonus on Day 7 of nonmedicated food treatment (C-Ich group; see Table 2) and sampled on Day 35 (28 d p.i.) Histological sections showing multinucleated spores in (A) heart, (B) liver and (C) head kidney. Staining: Toluidine blue
Table 6. Dicentrarchus labrax. Prevalence (\% in each experimental group; see Table 2) of Ichthyophonus sp. infection in control (C) and ketoconozole (KZ)-treated European sea bass. p.t.: after the start of the treatment; p.i.: post-injection

\begin{tabular}{|lcc|}
\hline \multirow{2}{*}{ Group } & \multicolumn{2}{c|}{ Prevalence (\%) } \\
\cline { 2 - 3 } & $\begin{array}{c}\text { Day 21 p.t. } \\
\text { (Day 14 p.i.) }\end{array}$ & $\begin{array}{c}\text { Day 35 p.t. } \\
\text { (Day 28 p.i.) }\end{array}$ \\
\hline C-Ich & 85.7 & 100 \\
KZ-Ich-40L & 64.3 & 81.3 \\
KZ-Ich-80L & 50 & 93.7 \\
KZ-Ich-40E & 57.1 & 93.7 \\
KZ-Ich-80E & 64.3 & 62.5 \\
\hline
\end{tabular}
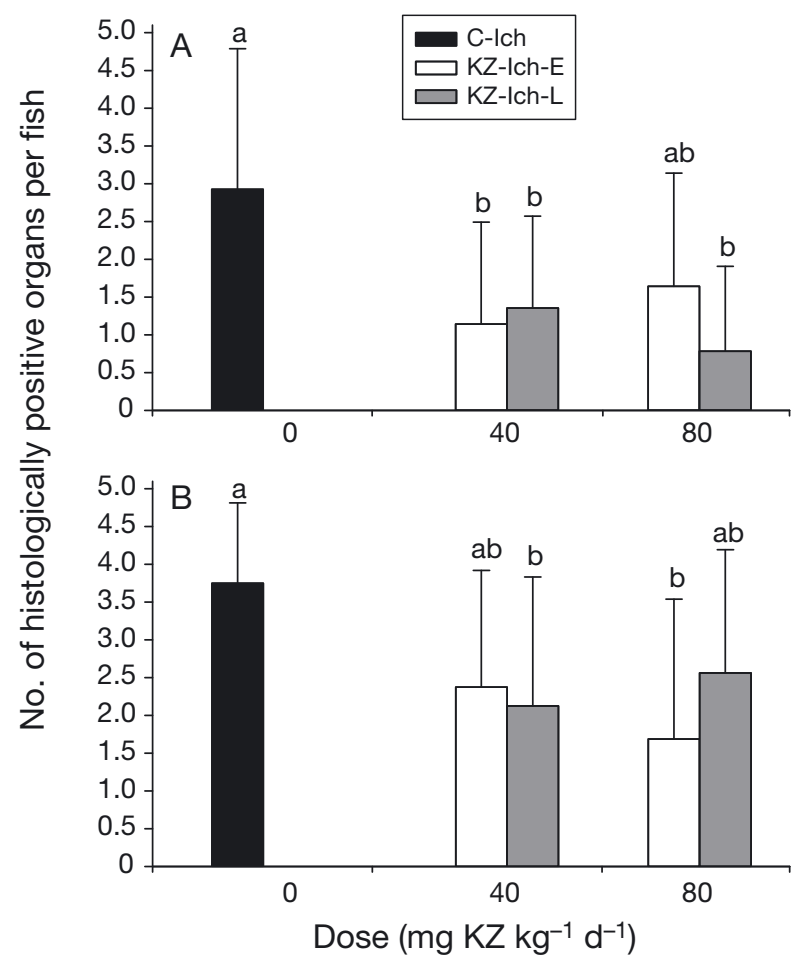

Fig. 12. Dicentrarchus labrax. Mean (+SD) number of histologically positive organs in control and ketoconazolemedicated European sea bass (see Table 2 for group abbreviations) after experimental injection with Ichthyophonus and medicated treatment for (A) $21 \mathrm{~d}$ and (B) $35 \mathrm{~d}$. Different letters show significant differences (ANOVA and GamesHowell tests; $\mathrm{p} \leq 0.05$ )

\section{DISCUSSION}

\section{Toxicity test}

The toxicity of KZ for healthy European sea bass Dicentrarchus labrax was demonstrated in terms of survival, haematology and histopathology, and it was dose dependent. Some of the toxic effects of KZ ap- 


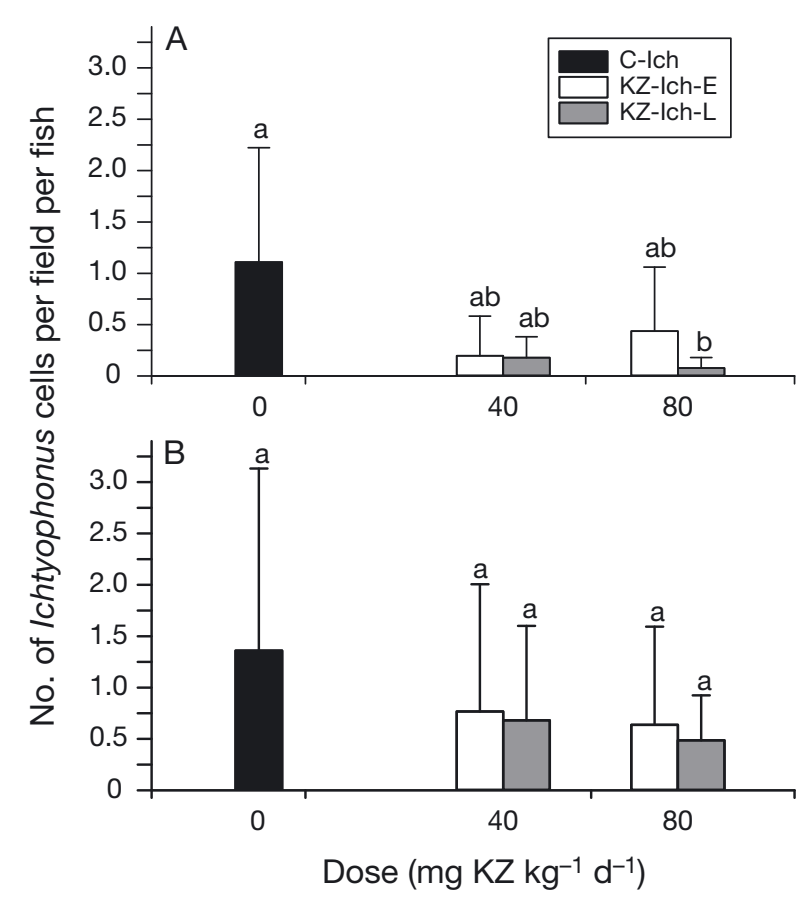

Fig. 13. Dicentrarchus labrax. Mean (+SD) number of Ichthyophonus cells in organ histological sections of control and ketoconazole-medicated European sea bass after experimental injection with Ichthyophonus and medicated treatment for (A) $21 \mathrm{~d}$ and (B) $35 \mathrm{~d}$. Different letters show significant differences (ANOVA and Games-Howell tests; $\mathrm{p} \leq 0.05)$

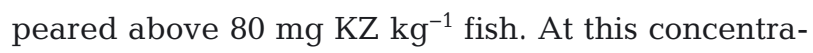
tion, $90 \%$ of the fish survived to the end of the treatment period, whereas only $5 \%$ of European sea bass

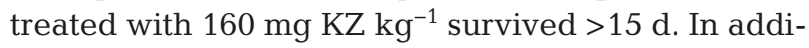
tion, histopathological alterations were observed in kidney, spleen and liver of these KZ-160L fish. However, none or only slight effects were seen with lower doses, suggesting low or no toxicity. In contrast, $100 \mathrm{mg} \mathrm{KZ} \mathrm{kg}{ }^{-1}$ produced severe hepatic damage in rats, including histopatological alterations and an increase in lipid peroxidation (Amin \& Hamza 2005). Liver toxicity is one of the side effects described for $\mathrm{KZ}$ in various organisms, including mammals, due to inhibition of the cytochrome P450-related biotransformation processes (Fink-Gremmels 2008), resulting in inhibition of mitochondrial functions (Feldman 1986, Rodríguez \& Acosta 1996). A similar effect seems to also occur in fish, as KZ strongly inhibited the activity of several hepatic P450-mediated monooxygenases in $\beta$-naftoflavone-treated trout (Miranda et al. 1998). Other studies have shown that KZ compromises the function of key P450 enzymes involved in the clearance of xenobiotics and steroids, and in- creases the sensitivity to 17 - $\alpha$-ethynylestradiol exposure in rainbow trout (Hasselberg et al. 2008). Whether such mechanisms could be involved in the slighter effects of KZ on ESB needs further investigation. In any case, a lower KZ absorption or a compensatory effect of the lipids delivered with liposomes may also be involved.

In KZ-treated sea bass, Hb was higher in KZ-20L, KZ-80L and KZ-160L fish than in the control group, whereas RBC changed only in KZ-160L fish, with values clearly higher than those in control fish. Thus, treated fish apparently try to compensate for possible peroxidation, as described in rats (Amin \& Hamza 2005), with an increase in the oxygen transporter. Consequently, $\mathrm{Hb}$ concentration in erythrocytes (MHC and MCHC) was also higher in KZ-20L than in control fish. In the KZ-160 fish, a low Hc, accompanied by a high $\mathrm{RBC}$, indicates the smaller size of erythrocytes, as is reflected in the low MCV. Considering the toxicity of KZ-160L, the doses for the in vivo treatment of experimentally infected fish were fixed below this value.

\section{Experimental treatments}

The data obtained in this study indicate that Ichthyophonus is clearly affected by the treatment with $\mathrm{KZ}$ in vivo in experimentally infected fish. Hontoria et al. (2009) already demonstrated the in vitro effect of this antifungal agent on Ichthyophonus. The effect of $\mathrm{KZ}$ on infection was time-dependent, as the prevalence of Ichthyophonus infection in medicated fish was much lower than in C-Ich fish during the initial stages after the experimental infection (14 d p.i.), whereas it increased markedly 2 wk later (28 d p.i.) in all treated groups except KZ-Ich-80E, reaching values similar to those of $\mathrm{C}$ groups in the previous sampling. In any case, the prevalence of infection was still lower in all treated groups than in the C-Ich group. Therefore, the medication seems to delay the onset of infection, but cannot stop its further progression once established. It is tempting to suggest that the delaying effect of KZ could be increased if lower infective doses (more similar to those of natural infections) were used. There were no clear differences between the 2 types of lipidic vehicles utilised (liposomes or emulsions), in terms of prevalence of infection. This contrasts with earlier data which indicate that in vitro cultures of Ichthyophonus are more sensitive to liposomated KZ formulations (Hontoria et al. 2009). These differences could be due to inevitable variations in chemotherapeutant modes of action 
between in vivo and in vitro systems or to increased difficulties in targeting tissues with $\mathrm{KZ}$, as Ichthyophonus spores tend to be surrounded by areas of granulomatous reaction or even encapsulated by layers of connective tissue (Franco-Sierra et al. 1997).

Our results contradict those obtained by FrancoSierra (1994), who did not find the same oral doses of liposomated KZ to be preventive in European sea bass experimentally infected with Ichthyophonus, when using fish smaller than those studied here $(14.3$ vs. $45 \mathrm{~g})$. The differences in the physiology and immune system of the fish due to age could explain such variable outcomes, since the bioavailability and toxicity of drugs and pollutants (Duffy et al. 2002), the level of parasite infection (Scotland et al. 1990, Khan 2012) and the functions of the fish immune system are all age-dependent processes (Dalmo 2005).

In previous studies (Franco-Sierra 1994), orally treated European sea bass did not show changes in haematological values either. Similarly, in the current experiments, oral (feed) administration of $\mathrm{KZ}$ did not produce significant differences between haematological values of the $\mathrm{C}$ group and any of the treated groups, whereas its injected administration did (even at the lowest dose). This was probably due to the higher and faster bioavailability of the drug when injected i.c. than when administered orally. Only the values of $\mathrm{Hc}, \mathrm{MCV}$ and $\mathrm{MHCH}$ of KZ-Ich-80L fish differed significantly from those of KZ-Ich-80E fish. These differences were probably related to the effect of the formulation, as liposomes may increase erythrocyte size and subsequently lower corpuscular $\mathrm{Hb}$ concentration.

The increase in lipids provided by the vehicles employed to deliver the antifungal agent may counterbalance the effect of $\mathrm{KZ}$ and be responsible for increased Ichthyophonus growth (Franco-Sierra 1994). The weaker effect of the treatments at the end of the experiment, which is apparent in the counts of spores in organ histological sections and in the number of infected organs, may have been caused by the extra lipids made available through the medicated food; these may have been used by Ichthyophonus to compensate for the effects of $\mathrm{KZ}$ and decrease its efficiency in the final stages of the experiment. As the infection progresses, fish react by encapsulating the spores in granulomata. Though Ichthyophonus appeared necrotic in some granulomata, spores were alive and viable in other cases. Thus, at the end the experiment, the granuloma wall may, to a certain extent, block the access of KZ to the parasite.

The results of the current work confirmed the potential of $\mathrm{KZ}$ in the treatment of ichthyophoniasis, though further research is needed to establish the optimal dose and application protocol. It is still to be determined whether KZ should be used preventively, and thus included in the food of certain fish, or as a curative measure for certain valuable specimens after they have shown the first symptoms of infection. The use of KZ to potentiate the effect of other treatments, as recently reported for some helminths (Bartley et al. 2012, Devine et al. 2012), could also be explored. In addition, the relatively low toxicity observed in sea bass endorses the use of the recognised antifungal properties of the azol-derivatives in fish.

Acknowledgements. These studies were funded by the PETRI program (Ref. PTR93-0073) of the R+D National Plan of the Spanish Government. The authors thank J. Montfort and L. Rodríguez for histological processing.

\section{LITERATURE CITED}

Adl SM, Simpson AGB, Farmer MA, Andersen RA and others (2005) The new higher level classification of eukaryotes with emphasis on the taxonomy of protists. J Eukaryot Microbiol 52:399-451

Amin A, Hamza AA (2005) Oxidative stress mediates druginduced hepatotoxicity in rats: a possible role of DNA fragmentation. Toxicology 208:367-375

> Bangham AD, Standish MM, Watkins JC (1965) Diffusion of univalent ions across the lamellae of swollen phospholipids. J Mol Biol 13:238-252

Bartley DJ, Morrison AA, Dupuy J, Bartley Y and others (2012) Influence of Pluronic 85 and ketoconazole on disposition and efficacy of ivermectin in sheep infected with a multiple resistant Haemonchus contortus isolate. Vet Parasitol 187:464-472

Brown MB, Forsythe AB (1974) Robust tests for the equality of variances. J Am Stat Assoc 69:364-367

Caullery M, Mesnil F (1905) Recherches sur les haplosporidies. Arch Zool Exp Gen (Ser 4) 4:101-180

Chauvier G, Mortier-Gabet J (1982) Recherches sur les possibilités de traitment chimique de l'Ichthyophonose. Rev Fr Aquariol 9:90

> Dalmo RA (2005) Ontogeny of the fish immune system. Fish Shellfish Immunol 19:395-396

> Devine C, Brennan GP, Lanusse E, Alvarez LI, Trudgett A, Hoey E, Fairweather I (2012) Potentiation of triclabendazole action in vivo against a triclabendazole-resistant isolate of Fasciola hepatica following its co-administration with the metabolic inhibitor, ketoconazole. Vet Parasitol 184:37-47

> Duffy JE, Carlson E, Li Y, Prophete C, Zelikoff JT (2002) Impact of polychlorinated biphenyls (PCBs) on the immune function of fish: age as a variable in determining adverse outcome. Mar Environ Res 54:559-563

Feldman D (1986) Ketoconazole and other imidazole derivatives as inhibitors of steroidogenesis. Endocr Rev 7: 409-420

Fink-Gremmels J (2008) Implications of hepatic cytochrome P450-related biotransformation processes in veterinary sciences. Eur J Pharmacol 585:502-509 
Franco-Sierra A (1994) Estudio de las infecciones por el hongo Ichthyophonus sp. en peces de interés comercial. $\mathrm{PhD}$ thesis, Publicacions de la Universitat Autónoma de Barcelona, Bellaterra (Barcelona)

Franco-Sierra A, Alvarez-Pellitero P (1999) The morphology of Ichthyophonus in their mugilid hosts (Pisces: Teleostei) and following cultivation in vitro. A light and electron microscopy study. Parasitol Res 85:562-575

Franco-Sierra A, Sitjà-Bobadilla A, Alvarez-Pellitero $P$ (1997) Ichthyophonus infections in cultured marine fish from Spain. J Fish Biol 51:830-839

Games PA, Howell JF (1976) Pairwise multiple comparison procedures with unequal N's and/or variances: a Monte Carlo study. J Educ Behav Stat 1:113-125

Gregoriadis G (1995) Engineering liposomes for drug delivery: progress and problems. Trends Biotechnol 13: 527-537

Hasselberg L, Westerberg S, Wassmur B, Celander MC (2008) Ketoconazole, an antifungal imidazole increases the sensitivity of rainbow trout to $17 \alpha$-ethynylestradiol exposure. Aquat Toxicol 86:256-264

> Hershberger PK, van der Leeuw BK, Gregg JL, Grady CA and others (2010) Amplification and transport of an endemic fish disease by an introduced species. Biol Invasions 12:3665-3675

Hofer B (1893) Eine Salmoniden-Erkrankung. Allg Fischztg 18:168-171

> Hontoria F, Crowe JH, Crowe LM, Amat F (1994) Potential use of liposomes in larviculture as a delivery system through Artemia nauplii. Aquaculture 127:255-264

Hontoria F, González MA, Sitjà-Bobadilla A, Palenzuela O, Alvarez-Pellitero P (2009) Ketoconazole inhibits the growth and development of Ichthyophonus sp. (Mesomycetozoa) in vitro. J Eukaryot Microbiol 56:484-491

Jesorka A, Orwar O (2008) Liposomes: technologies and analytical applications. Annu Rev Anal Chem 1:801-832

Khan RA (2012) Host-parasite interactions in some fish species. J Parasitol Res 2012:237280

Marty GD, Hulson PJF, Miller SE, Quinn TJ II, Moffitt SD, Merizon RA (2010) Failure of population recovery in relation to disease in Pacific herring. Dis Aquat Org 90: $1-14$

McVicar AH (1982) Ichthyophonus infections in fish. In: Roberts RJ (ed) Microbial diseases of fish. Academic Press, London, p 243-269

McVicar AH (1998) Ichthyophonus and related organisms.

Editorial responsibility: Dieter Steinhagen,

Hannover, Germany
In: Woo PTK, Bruno DW (eds) Fish diseases and disorders, Vol 3: Viral, bacterial and fungal infections. CABI Publishing, New York, NY, p 661-687

- Mehta RT (1996) Liposome encapsulation of clofazimine reduces toxicity in vitro and in vivo and improves therapeutic efficacy in the beige mouse model of disseminated Mycobacterium avium-M. intracellulare complex infection. Antimicrob Agents Chemother 40:1893-1902

> Mendoza L, Taylor JW, Ajello L (2002) The Class Mesomycetozoea: a heterogeneous group of microorganisms at the animal-fungal boundary. Annu Rev Microbiol 56: 315-344

> Miranda CL, Henderson MC, Buhler DR (1998) Evaluation of chemicals as inhibitors of trout cytochrome P450s. Toxicol Appl Pharmacol 148:237-244

Plehn M, Mulsow K (1911) Der Erreger der 'Taumelkrankheit' der Salmoniden. Zentbl Bakteriol Parasitenkd Infektionskrankh Hyg Orig 59:63-68

Ragan MA, Goggins CL, Cawthorn RJ, Cerenius L and others (1996) A novel clade of protistan parasites near the animal-fungal divergence. Proc Natl Acad Sci USA 93:11907-11912

Reichenbach-Klinke H, Elkan K (1965) Principal diseases of lower vertebrates. Academic Press, New York, NY

> Rodríguez RJ, Acosta D Jr (1996) Inhibition of mitochondrial function in isolated rat liver mitochondria by azole antifungals. J Biochem Toxicol 11:127-131

Scotland LM, Dobos P, Stevenson RMW (1990) Fry age and size effects on immersion immunization of brook trout, Salvelinus fontinalis Mitchell, against infectious pancreatic necrosis virus. J Fish Dis 13:113-125

Spanggaard B, Skouboe P, Rossen L, Taylor JW (1996) Phylogenetic relationships of the intracellular fish pathogen Ichthyophonus hoferi and fungi, choanoflagellates and the rosette agent. Mar Biol 126:109-115

Torchilin VP (2005) Recent advances with liposomes as pharmaceutical carriers. Nat Rev Drug Discov 4:145-160

> Vanden Bossche H, Marichal P, Gorrens J, Geerts H, Janssen PAJ (1988) Mode of action studies. Basis for the search of new antifungal drugs. Ann NY Acad Sci 544: 191-207

Van Duijn C Jr (1956) Diseases of fish. Iliffe Books, London

> Wang YJ, Yu CF, Chen LC, Chen CH and others (2002) Ketoconazole potentiates terfenadine-induced apoptosis in human Hep G2 cells through inhibition of cytochrome p450 3A4 activity. J Cell Biochem 87:147-159

Submitted: October 31, 2012; Accepted: March 28, 2013

Proofs received from author(s): July 16, 2013 